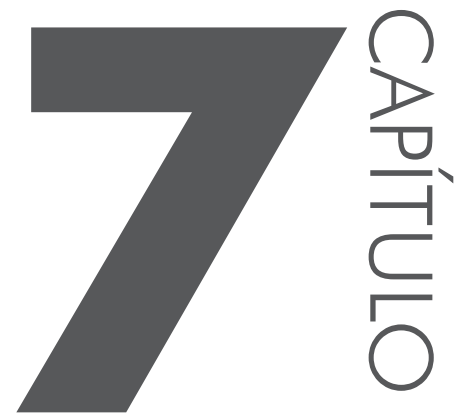

\title{
POLÍTICA ECONÔMICA DO FPM - 2005 A 2014: UMA ANÁLISE DOS REPASSES AOS MUNICÍPIOS DE CATALÃO-GO E RIO DAS OSTRAS-RJ
}

\author{
Paulo Antônio M. Hordones ${ }^{1}$ \\ Anayama A. Alves ${ }^{1}$ \\ Victor H. Camargo ${ }^{1}$ \\ Hélio Y. Fuchigami ${ }^{1}$
}

Resumo: O mecanismo de distribuição das receitas públicas no Brasil, alinhado ao pacto federativo, resulta em que as transferências constitucionais são

1 Unidade Acadêmica Especial de Gestão e Negócios, Universidade Federal de Goiás - Regional Catalão, Catalão, Brasil. E-mail de contato: ecn.pauloantonio@gmail.com 
consideradas uma das maiores fontes de receitas para as finanças municipais, gerando vínculos de dependência intensos entre os municípios e o governo federal. Este trabalho procurou contribuir para a compreensão dos critérios de rateio do fundo a partir do resgate histórico da evolução da legislação relacionadas ao tema. Foi apresentada evolução dos repasses dos municípios de Catalão-GO e Rio das Ostras-RJ no período de 2005 a 2014. Os resultados mostram que os repasses a Rio das Ostras cresceram $290 \%$ no período.

Palavras-chave: FPM. Gestão pública. Esforço tributário.

Abstract: The distribution mechanism of public revenues in Brazil, in line with the federal pact, results that the constitutional transfers are considered a major source of revenue for municipal finances, generating intense dependency links between municipalities and the federal government. This article sought to contribute to the understanding of the fund's apportionment criteria from the historical review of the evolution of legislation related to the theme. Were presented the evolution of transfers made to Catalão-GO and Rio das Ostras-RJ, from 2005 to 2014. The results show that the transfers to Rio das Ostras increased 290\% in the period.

Keywords: FPM. Public administration. Tax effort.

\section{INTRODUC̣ÃO}

De acordo com Hentz (2011), a organização político-administrativa da República Federativa do Brasil compreende três níveis governamentais autônomos e interdependentes, são eles: o governo federal, os estados e o Distrito Federal, e os municípios. As relações fiscais intergovernamentais foram estabelecidas pelo pacto federativo firmado na Constituição de 1988, que definiu as principais diretrizes tributárias, dispondo sobre os princípios gerais, as limitações do poder de tributar, as competências e também sobre a repartição das receitas tributárias.

As transferências constitucionais têm exercido um papel interessante e digno de análise no processo de busca da isonomia econômico-financeira e democrática entre estados e municípios no que tange à distribuição e à alocação dos recursos captados pelos entes federativos estaduais e municipais. Os sistemas de transferências intergovernamentais são dispositivos inerentes aos regimes federativos, considerados uma das principais formas de compatibilização dos interesses antagônicos dos diferentes níveis de governo, em que os subnacionais buscam mais autonomia fiscal, enquanto o governo central tende a centralizar as decisões de arrecadação e despesa.

Esses dispositivos se tornam mais relevantes à medida que se aumenta o grau de descentralização fiscal entre os níveis de governo, principalmente quando a distribuição das responsabilidades de gastos não é realizada de forma equilibrada 
com a repartição das competências tributárias, o que pode acentuar desequilíbrios fiscais verticais e horizontais, além de aumentar a dependência dos governos subnacionais em relação aos recursos do governo central. Os principais objetivos dos sistemas de transferências são a redução dos desequilíbrios fiscais e a coordenação dos entes subnacionais para o desenvolvimento de políticas do governo nacional.

O escopo desta análise foi o Fundo de Participação dos Municípios (FPM), por se tratar de uma fonte importante de recursos para os municípios cujo foco é a redução das desigualdades sociais e econômicas. O questionamento central deste trabalho foi como se comportaram, no período de 2005-2014, com a atual política econômica de redistribuição do FPM, os repasses feitos ao município de Catalão-GO em relação ao município de Rio das Ostras-RJ. O município fluminense foi selecionado como base para comparação por ter apresentado, no período mencionado, o maior crescimento populacional dentre todos os municípios brasileiros segundo o Instituto Brasileiro de Geografia e Estatística (IBGE).

Para responder ao problema da pesquisa, foi realizado um estudo do histórico concernente à política econômica de redistribuição do FPM desde sua criação até os dias atuais. A pesquisa pretendeu esclarecer, ainda que empiricamente, como ocorre a alocação dos recursos captados pelo governo na forma de tributos e impostos e a distribuição aos entes federativos municipais.

\section{EMBASAMENTO TEÓRICO}

Esta seção tem como referências: Câmara dos Deputados (2011), Gasparini e Melo (2004), Gasparini e Miranda (2006), Secretaria do Tesouro Nacional (2012), Tribunal de Contas da União (2010) e todos os dispositivos legais apresentados a seguir. Segundo Veloso (2008), o FPM é um instrumento de política fiscal federativa com o objetivo de suplementar os orçamentos dos municípios, buscando estabilidade, compensação e redistribuição dos recursos para esses entes subnacionais. De acordo com o inciso II do Art. 161 da Constituição Federal, o papel do FPM é promover o equilíbrio socioeconômico entre municípios.

O seu caráter redistributivo é justificado por este ser constituído de recursos provenientes de impostos cuja arrecadação se concentra nas localidades mais desenvolvidas e é distribuído basicamente por critério populacional, independente da base arrecadatória, conforme apresentado por Gasparini e Miranda (2006). A seguir será apresentada a sua evolução institucional e o sistema vigente.

\subsection{Histórico e evolução da legislação FPM no Brasil}

O FPM foi instituído pela Emenda Constitucional no 18, de 01/12/1965, a qual, em seu Art. 21 , destinava $20 \%$ do produto da arrecadação do Imposto 
sobre Produtos Industrializados (IPI) e do Imposto Sobre a Renda e Proventos de Qualquer Natureza (IR) ao Fundo de Participação dos estados e do Distrito Federal (FPE). O $\mathbb{S} 1^{\circ}$ do dispositivo remeteu à lei complementar o regramento da aplicação dos recursos; coube ao Código Tributário Nacional (CTN - Lei 5172/1966) estabelecer, no seu Art. 91, o critério de repartição do FPM com base nas populações municipais. Com a Constituição Federal (CF) de 1967, reduziu-se para $5 \%$ a participação do FPM no montante de arrecadação de IPI e IR e foram incluídas condições para a entrega das cotas aos Municípios.

A Emenda Constitucional (EC) $n^{\circ}$ 5, de 1975, elevou o percentual do FPM para 9\% por meio de um aumento gradual na seguinte forma: $6 \%, 7 \%, 8 \%$ e 9\%, correspondente aos exercícios de 1976, 1977, 1978 e 1979, respectivamente. Em 1980 a EC 17 elevou o percentual do FPM para 11\%, por meio de novo aumento gradual na seguinte forma: $10 \%, 10,5 \%$ e $11 \%$, correspondente aos exercícios de 1981, 1982 e 1984, respectivamente.

O Decreto Lei (DL) 1881 de 1981 alterou o CTN, criando a Reserva do FPM e modificando a tabela de coeficientes dos municípios não capitais. Na nova modalidade, exclusiva aos municípios com mais de 156.216 habitantes, foram destinados $4 \%$ dos recursos previstos para os municípios não capitais $(90 \%)$, ou seja, o equivalente a 3,6\% do montante do FPM. Portanto, aos municípios não capitais e com menos habitantes, restam 86,4\% dos recursos do FPM. Em 1987 a EC n ${ }^{\circ} 23$ elevou o percentual do FPM para 16\%. Em 1985 nova mudança: a EC $\mathrm{n}^{\circ} 27$ aumentou em mais 1 ponto percentual a composição do FPM e vinculou parte dos recursos à aplicação em programas de saúde.

A CF de 1988 elevou o percentual do FPM para 22,5\% por meio de um aumento gradual na seguinte forma: $20 \%$ em 1988, com acréscimos de 0,5\% a cada ano, atingindo $22,5 \%$ em 1993. A partir do novo texto constitucional, nada menos do que $47 \%$ dos recursos arrecadados pelo IR e pelo IPI passaram a ser destinados aos fundos dos estados e municípios. Ainda em 1988, a Lei Complementar (LC) 59 definiu que as revisões do número de habitantes e, consequentemente, dos coeficientes atribuídos aos municípios, a partir de 1989, passassem a ser anuais, com base nos dados oficiais da população produzidos pelo IBGE.

Em 1989, a LC 62 alterou a revisão dos coeficientes individuais de participação para que, no caso da criação e da instalação de novos municípios, o surgimento das novas unidades repercutisse somente nos municípios do próprio estado. A LC 71/1992 manteve os parâmetros fixos até que lei específica estabelecesse novos critérios. Em 1993, a LC 72 prorrogou as disposições da LC n 71 até 1993. No ano de 1993, a LC 74 manteve os coeficientes dos municípios determinados para 1992, além de revisar os daqueles que cederam população para novos municípios criados em 1993 e revogar a LC nº 71/1992. A EC 14/1996 determinou a criação do Fundo de Manutenção e Desenvolvimento do Ensino Fundamental 
e de Valorização do Magistério (Fundef) por meio da vinculação de, no mínimo, $15 \%$ dos recursos do FPM.

Em 1997 a LC 91 determinou que, a partir do exercício de 1998, ficariam mantidos os coeficientes do FPM atribuídos em 1997 aos municípios que apresentarem redução de seus coeficientes pela aplicação do coeficiente populacional. A partir de 1999, os ganhos adicionais em virtude da manutenção do coeficiente sofreriam aplicação de um "redutor financeiro", a ser aplicado até 2002, cujo resultado seria automaticamente redistribuído aos demais Municípios da categoria.

A LC 106/2001 alterou os percentuais de aplicação do redutor financeiro de tal forma que a regularização ocorreu no exercício de 2008. Uma alteração importante foi introduzida pela EC 55/2007, que acrescentou 1 ponto percentual ao FPM (que assim passou a ter alíquota de 23,5\%); este percentual a mais, entretanto, passou a ser acumulado na Conta Única do Tesouro Nacional ao longo de 12 meses, para ser entregue aos municípios por seu valor integral no primeiro decêndio de dezembro de cada ano. A Figura 1 ilustra o acima exposto numa linha de tempo.

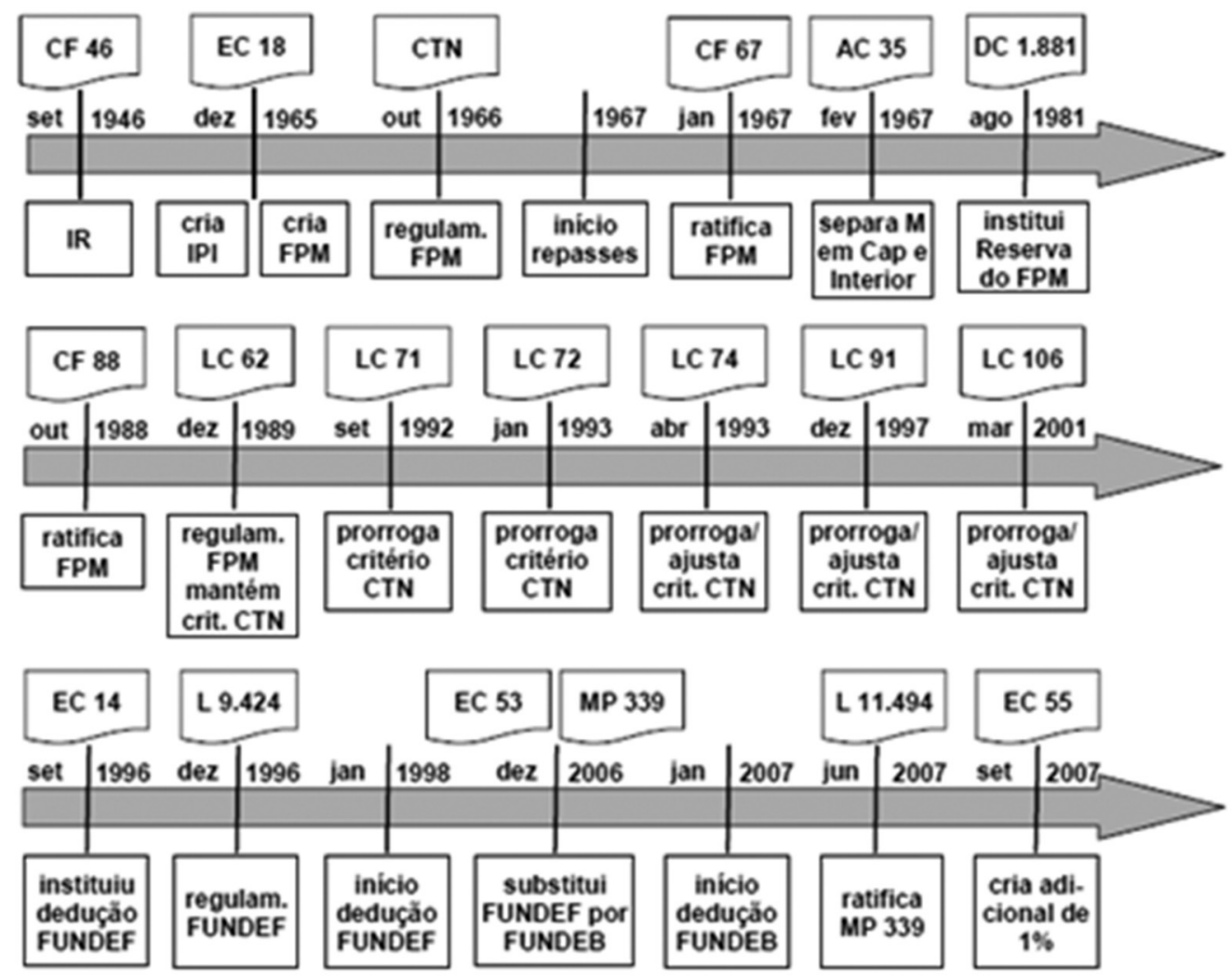

Figura 1. Histórico da legislação sobre FPM. Fonte: Secretaria do Tesouro Nacional, 2013. 
Efetivamente, a partir de setembro de 2008, o montante do FPM passou a ser composto de $23,5 \%$ da arrecadação líquida do IPI e do IR, sendo deduzido desse valor os $15 \%$ do Fundef. A arrecadação bruta desses impostos é apurada decenalmente pela Receita Federal do Brasil (RFB), que deduz as restituições e incentivos fiscais ocorridos no mesmo período e comunica o montante da arrecadação líquida resultante à Secretaria do Tesouro Nacional (STN). Esta secretaria realiza a contabilização dessas arrecadações líquidas no Sistema Integrado de Administração Financeira do Governo Federal (SIAFI), informando em seguida ao Banco do Brasil o montante financeiro a ser transferido. O Banco do Brasil calcula o valor da cota de cada município, de acordo com os coeficientes definidos pelo TCU e com o valor total do FPM fornecido pela STN, e realiza a distribuição dos recursos aos municípios.

As cotas de participação do FPM são fixadas pelo TCU com base nas populações de cada município brasileiro e no PIB per capita das unidades da federação, ambos fornecidos pelo IBGE, sendo que as informações sobre a renda não são necessariamente do período vigente. O IBGE envia ao TCU até o dia 31 de outubro de cada exercício as informações populacionais de cada município, de acordo com o Art. 102 da Lei no 8.443, de 16 de julho de 1992. Após a formulação, até o último dia útil de cada exercício, o TCU publica no Diário Oficial da União e comunica ao Banco do Brasil e à STN os coeficientes individuais de participação dos municípios, que terão vigência durante todo o exercício seguinte, de acordo com a Decisão no $1.121 / 2000$ e no $853 / 2000$ do TCU.

\subsection{Distribuição do FPM}

O FPM é o resultado da receita bruta do IR e do IPI deduzidos as restituições e os incentivos fiscais. A esse resultado líquido aplica-se uma alíquota de 23,5\% a ser destinada ao fundo. O cálculo do coeficiente individual do FPM para cada município, obtido através dos dados da população e da renda per capita disponibilizados pelo IBGE estabelece a formação de três grupos para a distribuição dos recursos: os municípios das capitais; os municípios pertencentes ao Fundo de Reserva, que são os municípios com população superior a 142.633 habitantes; e os municípios do interior.

A Tabela 1 demonstra a evolução das alíquotas de formação do FPM a partir de 1967, que parte de 10\% sobre o volume arrecadado de IPI e IR. Entre 1969 e 1975, essa alíquota passou a ser de $5 \%$ e, a partir daí, há um crescimento até atingir 17\% em 1988. Com a nova Constituição Federal de 1988, define-se um novo parâmetro de evolução que, em 2007, chega a 23,5\%, alíquota que continua em vigor. 
Tabela 1. Evolução dos percentuais do FPM

\begin{tabular}{ccc}
\hline Dispositivo Legal & FPM (\%) & Vigência \\
\hline Código Tributário Nacional (1966) & 10,0 & $1967 / 68$ \\
Ato Complementar 40/1968 & 5,0 & $1969 / 75$ \\
& 6,0 & 1976 \\
Emenda Constitucional 5/1975 & 7,0 & 1977 \\
& 8,0 & 1978 \\
Emenda Constitucional 17/1980 & 9,0 & $1979 / 80$ \\
& 10,0 & 1981 \\
Emenda Constitucional 23/1983 & 10,5 & $1982 / 83$ \\
Emenda Constitucional 27/1985 & 13,5 & 1984 \\
Constituição Federal de 1988 & 16,0 & 1985 \\
& 17,0 & $1985 / 88$ \\
& 20,0 & $1988($ (a) \\
& 20,5 & 1989 \\
& 21,0 & 1990 \\
Emenda Constitucional 55/2007 & 21,5 & 1991 \\
\hline
\end{tabular}

(a) A partir da promulgação da Constituição.

(b) Em 2007, a partir da arrecadação do mês de setembro.

Fonte: Secretaria do Tesouro Nacional, 2013.

A repartição dos recursos do FPM ocorre da seguinte forma: $10 \%$ aos municípios das capitais dos estados, 3,6\% para os municípios do interior incluídos na Reserva do FPM e 86,4\% aos municípios do interior. Essas categorias são apresentadas a seguir na Tabela 2.

Tabela 2. Percentuais de distribuição do FPM

\begin{tabular}{cccc}
\hline FPM - CAPITAIS & FPM - INTERIOR & $\begin{array}{c}\text { DECRETO - Lei } 1.881 / 81 \\
\text { Fundo de Reserva }\end{array}$ & FPM LíQUIDO \\
\hline $10 \%$ & $86,4 \%$ & $3,6 \%$ & $100 \%$ \\
\hline
\end{tabular}

A cota de FPM recebida por um dado município é calculada com base em coeficientes de participação definidos segundo critérios populacionais, conforme Tabela 3. O coeficiente mínimo, 0,6, é estabelecido para municípios com 
até 10.188 habitantes. Para municípios cuja população situa-se entre 10.188 e 156.216 habitantes, foram definidas 18 faixas populacionais, cabendo a cada uma delas coeficiente individual. Para todos os municípios do interior com mais de 156.216 habitantes foi determinado o coeficiente 4,0.

Tabela 3. FPM Interior - coeficientes por faixa de habitantes

\begin{tabular}{cc}
\hline Faixa de habitantes & Coeficiente \\
\hline Até 10.188 & 0,6 \\
De 10.189 a 13.584 & 0,8 \\
De 13.585 a 16.980 & 1,0 \\
De 16.981 a 23.772 & 1,2 \\
De 23.773 a 30.564 & 1,4 \\
De 30.565 a 37.356 & 1,6 \\
De 37.357 a 44.148 & 1,8 \\
De 44.149 a 50.940 & 2,0 \\
De 50.941 a 61.128 & 2,2 \\
De 61.129 a 71.316 & 2,4 \\
De 71.317 a 81.504 & 2,6 \\
De 81.505 a 91.692 & 2,8 \\
De 91.693 a 101.880 & 3,0 \\
De 101.881 a 115.464 & 3,2 \\
De 115.465 a 129.048 & 3,4 \\
De 129.049 a 142.632 & 3,6 \\
De 142.633 a 156.216 & 3,8 \\
Acima de 156.216 & 4,0 \\
\hline
\end{tabular}

Fonte: adaptada de Secretaria do Tesouro Nacional, 2013.

\section{METODOLOGIA}

Segundo as definições de Martins (2010) e Nakano (2010), esta pesquisa possui abordagem quantitativa, pois há preocupação com mensurabilidade, causalidade, generalização e replicação. Pode ser classificada também como pesquisa aplicada, uma vez que objetiva gerar conhecimentos para aplicação prática dirigidos à solução de problemas específicos e envolve verdades e interesses locais. Além disso, de acordo com Gerhardt e Silveira (2009), este trabalho se classifica como pesquisa documental, uma vez que recorre a fontes diversificadas e dispersas, sem tratamento analítico. Do ponto de vista dos procedimentos técnicos, a base de dados utilizada é proveniente da STN e do IBGE, informações disponibilizadas em sites governamentais e, por conseguinte, análise estatística. 


\section{RESULTADOS}

A Figura 2 demonstra uma evolução nos valores nominais dos recursos que foram repassados aos municípios de 2003 a 2012. Pode-se observar de forma clara o crescimento do volume de recursos recebidos pelos municípios e a evolução nos valores nominais do fundo, reflexo da arrecadação geral dos impostos federais que o forma.

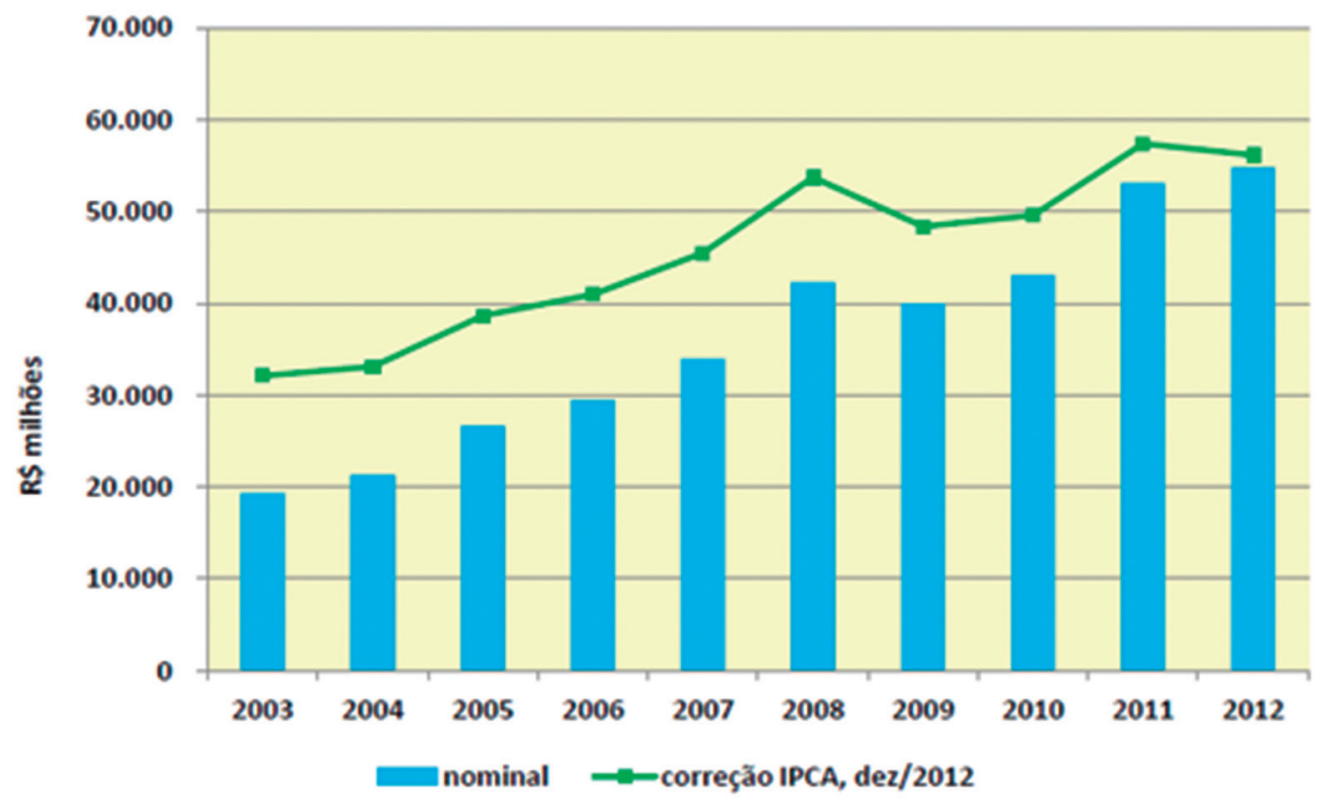

Figura 2. Evolução anual das transferências intergovernamentais do FPM. Fonte: Secretaria do Tesouro Nacional, 2013.

Nota-se claramente que o repasse saiu de algo em torno de 32 bilhões de reais em 2003 para chegar em 2012 na casa dos 58 bilhões de reais. Esta evolução corresponde a um crescimento anualizado na faixa dos $6,13 \%$. No mesmo período, o PIB brasileiro apresentou crescimento médio de $3,79 \%$ ao ano com um pico em 2010 que chegou a 7,6\%, segundo o IBGE. A Tabela 4 demonstra a evolução populacional e os repasses per capita do FPM para os municípios de Catalão e Rio das Ostras.

Ao acompanhar a evolução do repasse do FPM na Tabela 4, verifica-se que, em 2005, Rio das Ostras recebia pouco mais de $76 \%$ do valor recebido por Catalão. Em 2014, a cidade fluminense passou a receber 104\% do valor repassado à cidade goiana. 
Tabela 4. Evoluções de população, repasses do FPM e repasses per capita do FPM para os municípios de Catalão e Rio das Ostras de 2005 a 2014

\begin{tabular}{|c|c|c|c|c|c|}
\hline \multicolumn{6}{|c|}{ Catalão - GO } \\
\hline \multirow{2}{*}{\begin{tabular}{l|} 
Ano \\
2.005 \\
\end{tabular}} & \multicolumn{2}{|c|}{ Volume Total } & \multirow{2}{*}{\begin{tabular}{|r|} 
População \\
$\mathbf{7 0 . 5 7 4}$ \\
\end{tabular}} & \multicolumn{2}{|c|}{ FPM/Per capita } \\
\hline & RS & $8.991 .494,87$ & & R\$ & 127,41 \\
\hline 2.006 & RS & 9.989.171,30 & 71.680 & R\$ & 139,36 \\
\hline 2.007 & $\mathbf{R S}$ & $12.501 .297,57$ & 75.623 & R\$ & 165,31 \\
\hline 2.008 & RS & 15.526.251,91 & 79.618 & R\$ & 195,01 \\
\hline 2.009 & RS & $14.516 .590,98$ & 81.109 & R\$ & 178,98 \\
\hline 2.010 & RS & $15.602 .932,91$ & 86.647 & R\$ & 180,07 \\
\hline 2.011 & RS & $20.294 .725,70$ & 88.354 & R\$ & 229,70 \\
\hline 2.012 & RS & $20.907 .483,64$ & 90.004 & R\$ & 232,30 \\
\hline 2.013 & & $22.352 .782,18$ & 94.896 & R\$ & 235,55 \\
\hline 2.014 & RS & $25.729 .304,38$ & 96.836 & R\$ & 265,70 \\
\hline \multicolumn{6}{|c|}{ Rio das Ostras - RJ } \\
\hline 2.005 & RS & $6.883 .548,02$ & 47.819 & R\$ & 143,95 \\
\hline 2.006 & RS & 7.589.171,06 & 49.868 & R\$ & 152,19 \\
\hline 2.007 & RS & $8.721 .280,18$ & 74.750 & R\$ & 116,67 \\
\hline 2.008 & & $14.017 .932,90$ & 91.085 & R\$ & 153,90 \\
\hline 2.009 & & $14.063 .053,49$ & 96.622 & R\$ & 145,55 \\
\hline 2.010 & RS & $16.154 .577,00$ & 105.676 & $\mathbf{R} \mathbf{\$}$ & 152,87 \\
\hline 2.011 & & $21.176 .688,08$ & 110.992 & R\$ & 190,79 \\
\hline 2.012 & & 21.788.628,48 & 116.134 & R\$ & 187,62 \\
\hline 2.013 & & $24.767 .128,40$ & 122.196 & R\$ & 202,68 \\
\hline 2.014 & & $26.903 .800,12$ & 127.171 & R\$ & 211,56 \\
\hline
\end{tabular}

Fonte: adaptada de IBGE, 2014.

Na Figura 3, verifica-se que, no período de 2005 a 2014, Catalão teve um crescimento populacional médio da ordem de 3,21\% a.a., enquanto que a população de Rio das Ostras cresceu a taxas médias de 10,28\% a.a., sendo, segundo o IBGE (2014), o município brasileiro que apresentou maior crescimento populacional no período analisado. 


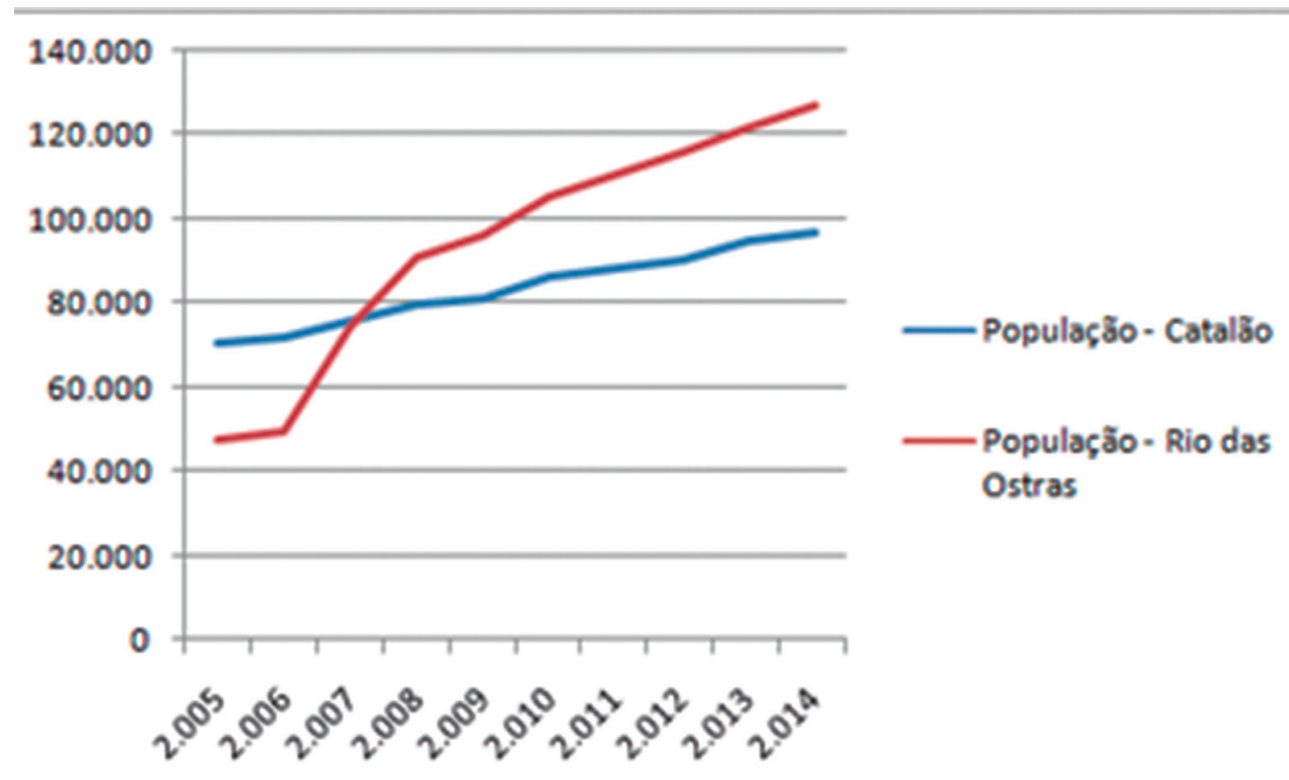

Figura 3. Evolução populacional dos municípios de Catalão e Rio das Ostras. Fonte: adaptada de IBGE, 2014.

$\mathrm{Na}$ Figura 4, pode-se observar que o crescimento do repasse per capita do FPM para o município de Catalão apresentou uma taxa de crescimento de 7,63\% a.a., enquanto o repasse per capita do FPM para o município de Rio das Ostras teve um crescimento médio de apenas 3,93\% a.a.

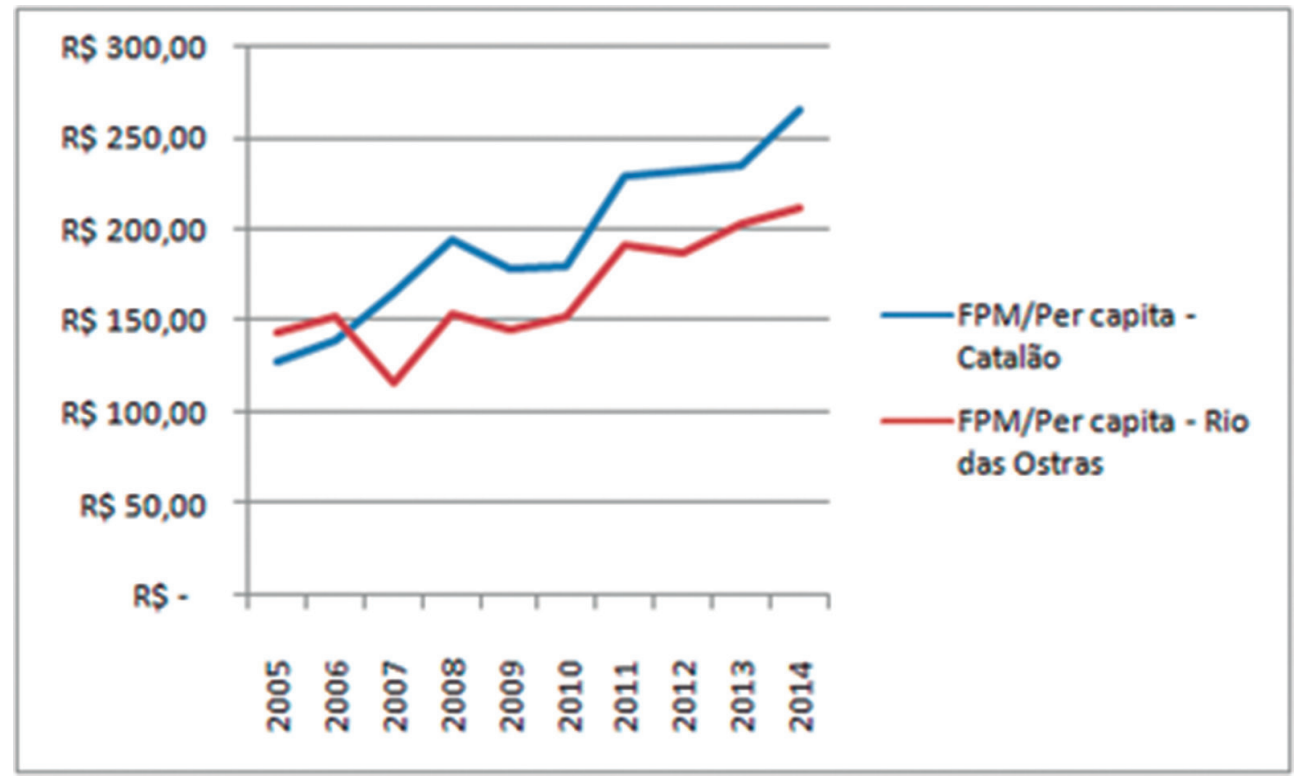

Figura 4. Repasse do FPM per capita para os municípios de Catalão e Rio das Ostras. Fonte: adaptada de IBGE, 2014. 


\section{CONCLUSÃO}

O FPM tem sua discussão associada ao federalismo fiscal, pertencente ao estudo das finanças públicas relacionadas à análise de divisão de competências e à prestação de serviços pelos entes federados e que, portanto, como já mencionado, estão atreladas ao critério de distribuição, com o intuito de promover igualdade e proporcionar eficiência na alocação dos recursos. $\mathrm{O}$ trabalho procurou contribuir para a compreensão dos critérios de rateio do fundo a partir do resgate histórico da evolução da legislação relacionadas ao tema.

Observou-se após a criação do FPM em 1965 uma tendência inicial de redução do percentual de recursos que o compõem, reduzindo o valor inicial de $10 \%$ para $5 \%$ a partir do Ato Complementar $n^{\circ} 40 / 1968$ e permanecendo constante até 1975 , o que indica um período de concentração de recursos por parte do governo federal. Em 1976, com a Emenda Constitucional $n^{\circ} 5 / 1975$, iniciou-se um gradativo aumento desse percentual, atingindo o valor de 10,5\% em 1983. No ano seguinte, com a Emenda Constitucional no 23/1983, iniciou-se uma aceleração dessa tendência de crescimento, atingindo o valor de 22,5\% em 1993, o que reflete um período de descentralização dos recursos, cujo marco principal é a Constituição Federal de 1988. Esse valor permaneceu constante até 2007, no qual a Emenda Constitucional $n^{\circ} 55$ o aumentou para 23,5\%.

No que diz respeito aos resultados, verifica-se, no período estudado, uma evolução nos valores nominais do FPM, reflexo da arrecadação geral dos impostos que o formam. Isso demonstra que o Governo teve sua arrecadação crescente neste período.

O município de Catalão apresentou aumento populacional total no período estudado de $37,21 \%$ e aumento dos repasses do fundo de $186 \%$. Já o município de Rio das Ostras apresentou o maior crescimento populacional do Brasil no período: $165,94 \%$. Esta cidade apresentou ainda um aumento nos repasses do fundo da ordem de $290 \%$.

No ano de 2005, o repasse per capita do FPM recebido por Catalão era menor do que o apresentado por Rio das Ostras. Já no ano de 2014, Catalão recebeu repasse per capita 25,59\% maior do que Rio das Ostras.

Para o desenvolvimento de futuros trabalhos, sugere-se a avaliação dos motivos que justificam um recebimento per capita maior por Catalão em relação a Rio das Ostras e a inclusão da capital goiana na base de comparação dos dados.

\section{REFERÊNCIAS}

ABRANTES, L. A. FERREIRA, M. A. M. Gestão Tributária. Florianópolis:

Departamento de Ciências e Administração - UFSC; Brasília: CAPES-UAB, 2010. 
BRASIL. Ato complementar n ${ }^{\circ} 35$, de 28 de fevereiro de 1967. Altera a Lei n ${ }^{\circ} 5.172$, de 25 de outubro de 1966 e legislação posterior sobre o Sistema Tributário Nacional. Diário Oficial da União, Brasília, 28 de fevereiro de 1967.

. Decreto-lei no 86.309 , de 24 de agosto de 1981. Reajusta os limites das fixas de números de habitantes de que trata o $\mathbb{2} 2^{\circ}$ do artigo 91 da Lei ${ }^{\circ} 5.172$, de 25 de outubro de 1966. Diário Oficial da União, Brasília, 24 de agosto de 1981.

. Decreto-lei $\mathrm{n}^{\circ} 1.881$, de 27 de agosto de 1981. Altera a Lei ${ }^{\circ}$ 5.172, de 25 de outubro de 1966, cria a Reserva do Fundo de Participação dos Municípios - FPM a dá outras providências. Diário Oficial da União, Brasília, 27 de agosto de 1981.

. Constituição da República Federativa do Brasil de 1988. Diário Oficial da União, Brasília, 5 de outubro de 1988.

. Emenda Constitucional n ${ }^{\circ}$ 55, de 20 de setembro de 2007. Altera o Art. 159 da Constituição Federal, aumentando a entrega de recursos pela União ao Fundo de Participação dos Municípios. Diário Oficial da União, Brasília, 20 de setembro de 2007.

. Câmara dos Deputados. Fundo de Participação dos Municípios e participações governamentais sobre a produção de petróleo e gás natural: comentários e revisão de critérios de repartição. Brasília: Câmara dos Deputados, 2011.

- Ministério da Fazenda. Secretaria do Tesouro Nacional. Finanças do Brasil: dados contábeis dos municípios. Banco de dados. Disponível em: <www.tesouro. fazenda.gov.br>. Acesso em: 10 dez. 2013.

. Ministério do Planejamento, Orçamento e Gestão. Secretaria de Orçamento Federal. Séries históricas de dados e indicadores fiscais. Brasília, 2007.

. Ministério da Fazenda. Secretaria do Tesouro Nacional. O que você precisa saber sobre transferências constitucionais e legais, Brasília, 2011. Disponível em: <http:// www.stn.fazenda.gov.br/estados_municipios/download/CartilhaFPM.pdf >. Acesso em: 2 jun. 2014.

GASPARINI, C.; MELO, C. Equidade e eficiência municipal: uma avaliação do Fundo de Participação dos Municípios (FPM). In: Finanças Públicas: VIII Prêmio Tesouro Nacional - 2003. Coletânea de monografias/Secretaria do Tesouro Nacional. Brasília: Editora da Universidade de Brasília, 2004, p. 345-401.

GASPARINI, C.; MIRANDA, R. Evolução dos aspectos legais e dos montantes de transferências realizadas pelo Fundo de Participação dos Municípios. Texto para Discussão, n. 1243. Brasília: IPEA, 2006.

GERHARDT, T. E.; SILVEIRA, D. T. (Org.) Métodos de pesquisa. Porto Alegre: Editora da UFRGS, 2009.

HENTZ, C. FPM: equidade e eficiência - estudo de casos do RS. 2011. Dissertação (Mestrado) - Faculdade de Ciências Econômicas, Universidade Federal do Rio Grande do Sul, Porto Alegre, 2011. 86 p.

IBGE. Instituto Brasileiro de Geografia e Estatística. Estimativas da população residente nos municípios brasileiros com data de referência em $1^{\circ}$ de julho de 2014. Brasília:

IBGE, 2014. 
Produto Interno Bruto dos municípios 2005-2013. Banco de dados. Disponível em: <www.ibge.gov.br>. Acesso em: 10 mai. 2014.

MARTINS, R. A. Abordagens quantitativa e qualitativa. In: MIGUEL, P. A. C. (Org.) Metodologia de pesquisa em engenharia de produção e gestão de operações. Rio de Janeiro: Elsevier, 2010, p. 45-61.

NAKANO, D. Métodos de pesquisa adotados na engenharia de produção e gestão de operações. In: MIGUEL, P. A. C. (Org.) Metodologia de pesquisa em engenharia de produção e gestão de operações. Rio de Janeiro: Elsevier, 2010, p. 63-72.

VELOSO, J. F. A. As transferências intergovernamentais e o esforço tributário municipal: uma análise do Fundo de Participação dos Municípios (FPM). Dissertação (Mestrado) - Faculdade de Ciências Econômicas, Universidade Católica de Brasília, Brasília, 2008. 113 p. 